\title{
Fine structure and morphogenesis of spironolactone bodies in the zona glomerulosa of the human adrenal cortex
}

\author{
K. KOVACS, E. HORVATH, AND W. SINGER \\ From the Departments of Pathology and Medicine, St Michael's Hospital, \\ University of Toronto. Toronto, Ontario, Canada
}

SYNOPSIS Numerous spironolactone bodies have been detected in the zona glomerulosa cells of the adrenal cortex of a 36-year-old spironolactone-treated woman whose non-tumorous right adrenal gland was removed surgically because of primary hyperaldosteronism. Electron microscopy revealed spherical laminated whorls which consisted of a central core composed of an amorphous electrondense material surrounded by numerous smooth-walled concentric membranes. Continuous with and deriving from the endoplasmic reticulum, they were present in viable cells and were not associated with ultrastructural features indicating cellular injury. Cytoplasmic inclusions similar to spironolactone bodies can be detected in other organs after the administration of various compounds. Thus, they can be regarded as neither specific to spironolactone treatment nor exclusively inducible in the zona glomerulosa of the adrenal cortex.

Spironolactone (Aldactone) bodies were first detected by Janigan (1963) in the zona glomerulosa of adrenal cortex of human subjects following prolonged treatment with spironolactone, an aldosterone antagonist. To our knowledge findings on the ultrastructure of these round, laminated, acidophilic inclusions have only been reported so far by Jenis and Hertzog (1969) and by Davis and Medline (1970). These authors examined human adrenal glands obtained from necropsies, and, as several hours elapsed between death and fixation of tissues, the preservation could not be considered optimal.

Recently, a non-tumorous adrenal gland, removed surgically from a 36-year-old woman because of primary hyperaldosteronism, was studied by electron microscopy in our laboratory. The zona glomerulosa of the adrenal cortex was found to contain numerous spironolactone bodies, thus providing an opportunity to investigate the fine structure, morphogenesis, and evolution of these distinctive cytoplasmic inclusions in well preserved specimens.

\section{Case History}

A 36-year-old housewife presented with a two-year history of spontaneous flushing and sweating attacks Received for publication 10 September 1973. and the recent onset of pounding headaches. Blood pressure was $220 / 120 \mathrm{~mm} \mathrm{Hg}$ bilaterally, unaffected by posture. Laboratory investigations revealed a normal haemogram, ESR, serum calcium and phosphorus, serum uric acid, ac and pc blood sugar, plasma cortisol (8 am and $8 \mathrm{pm}$ ), urinary 17-ketogenic and 17-ketosteroids, and VMA estimations including a search for raised metanephrine and normetanephrine levels. Rogitine failed to cause a sustained drop in her blood pressure. Serum electrolytes were normal initially and remained so throughout, with the exception of two low $\mathrm{K}$ values of 3.1 and 3.3 m-equiv/1 without evidence of associated metabolic alkalosis while off all medications.

Renin activity was depressed on a low (10 m-equiv/ 1) sodium diet but showed some postural response: $0.54 \mathrm{ng}$ angiotensin I supine (normal: $2.58 \pm 0.70$ ) and 2.99 $\mathrm{ng}$ angiotensin I upright (normal: 5.26 \pm 0.65) (Dr A. Bailey).

Suprarenal vein aldosterone showed a markedly raised value on the right but without suppression of the levels on the left on a high $\mathrm{Na}$ diet: right main suprarenal vein $69.3 \mathrm{ng} / 100 \mathrm{ml}$ (normal mean $21.2 \mathrm{ng}$ ); right inferior suprarenal vein $26.4 \mathrm{ng} / 100$ $\mathrm{ml}$; left main suprarenal vein $19.9 \mathrm{ng} / 100 \mathrm{ml}$ (normal mean $20.4 \mathrm{ng} / 100 \mathrm{ml}$ ) (Dr A. Solomon).

Her blood pressure remained permanently elevated. 
She responded suboptimally to Apresoline in doses of 150 to $200 \mathrm{mg} /$ day. Dexamethasone $(2 \mathrm{mg} /$ day for 10 days) had no effect on her blood pressure. Aldactone (spironolactone) in doses of 200 to 400 $\mathrm{mg} /$ day, promptly brought her blood pressure down to levels averaging $120 / 80$ with complete relief of her symptoms and initial diuresis. On discontinuing this drug blood pressure rose within four days to the previous levels. She was on Aldactone for a total of three months preoperatively.

She was subjected to right adrenalectomy ( $\mathrm{Dr}$ N. Struthers). Grossly the adrenal gland appeared normal. Renal biopsy did not show abnormalities.

Postoperatively she has thus far remained normotensive without drugs.

\section{Methods}

For light microscopy the adrenal gland was fixed in neutral formalin and embedded in paraffin. Sections were stained with haematoxylin-saffron-phloxine, PAS, and luxol fast blue.

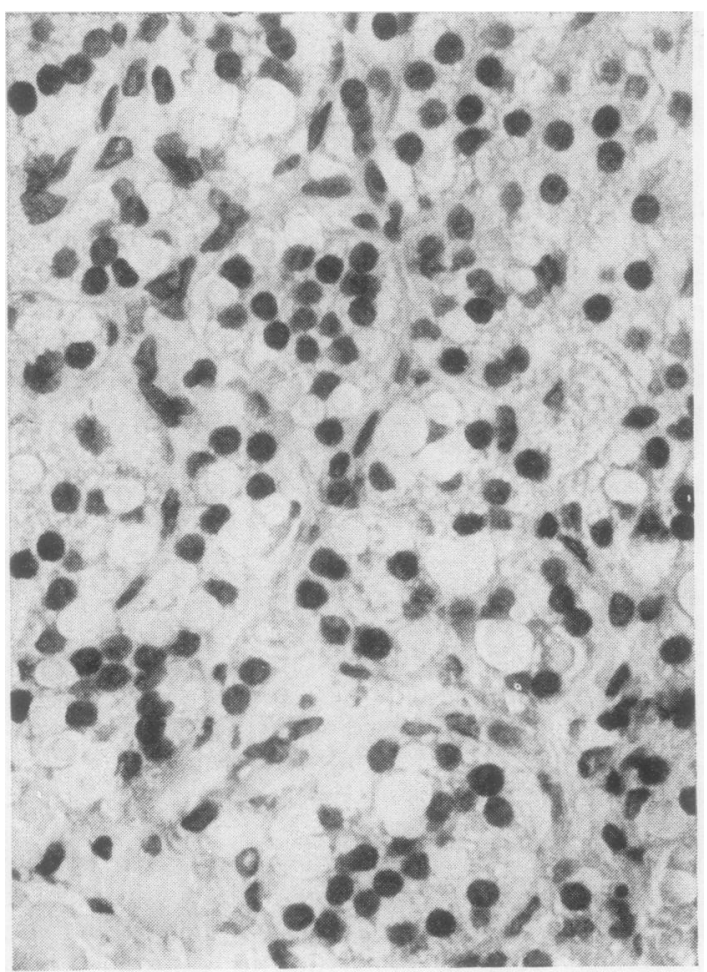

Fig 1
For electron microscopy specimens were fixed $\stackrel{\stackrel{0}{*}}{{ }^{\circ}}$ immediately after surgical removal of the adrenal gland. Pieces from the zona glomerulosa, as well $\overrightarrow{\vec{F}}$ as from the inner cortical layers, were fixed in $2.5 \%$ glutaraldehyde in $1.5 \mathrm{M}$ phosphate buffer, post- $\frac{C}{0}$ osmicated in Millonig's osmium fixative, dehydrated $\frac{\bar{\omega}}{\overline{0}}$. in graded ethanol, and embedded in Epon 812. Sections were cut with a Porter Blum MT-2 ultra- $\frac{2}{0}$ microtome, stained with toluidine blue. Suitable ${ }^{\infty}$ blocks were selected and the ultrathin sections, $\vec{O}$ stained with uranyl acetate and lead citrate, were $\overrightarrow{ }$ examined with a Philips 300 electron microscope.

\section{Results}

Histology revealed a somewhat wider zona glomer- $\vec{N}$ ulosa but otherwise the adrenal cortex did not exhibit 0 marked abnormalities. Only the light and electron 0 microscopic features of the spironolactone bodies 은 have been dealt with here.

By light microscopy numerous spironolactone $\underset{\mathbb{D}}{\overparen{1}}$ bodies were easily identified in the cytoplasm of the $\stackrel{\Phi}{\Phi}$

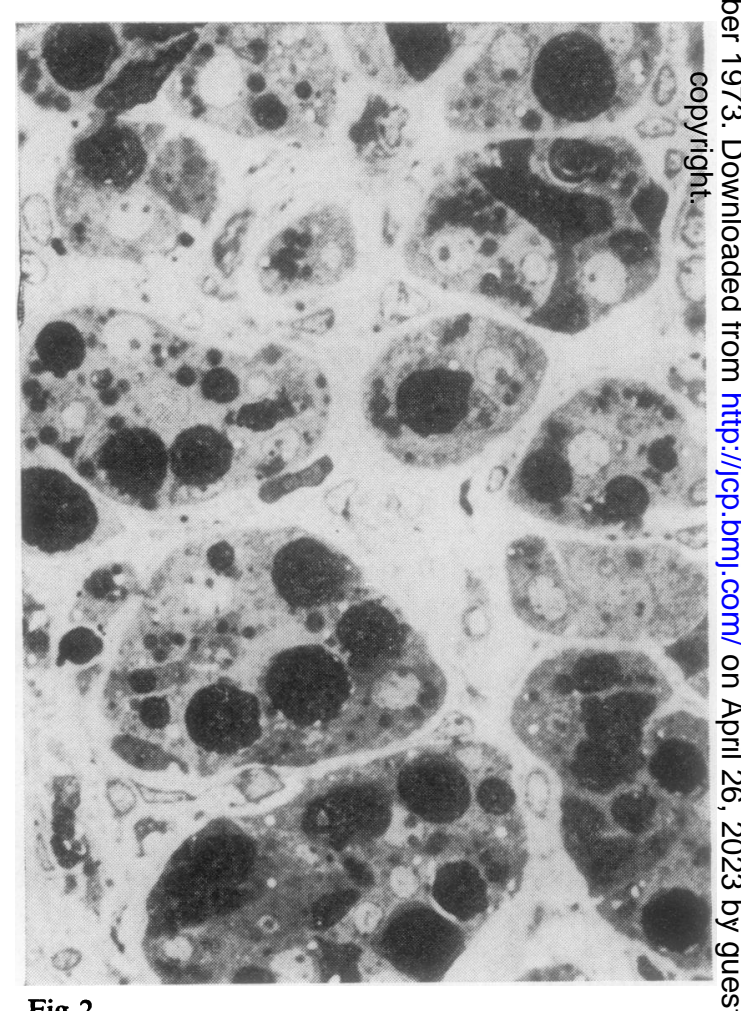

Fig 2

Fig 1 Light microscopy specimen showing large number of spironolactone bodies in the zona glomerulosa. Haematoxylin-saffron-phloxine. Approximately $\times 250$

Fig 2 Spironolactone bodies in toluidine blue stained epon section. Approximately $\times 400$ 
outer zona glomerulosa cells (figs 1, 2). Occasionally a few spironolactone bodies were also detected in the cytoplasm of the deeper zona glomerulosa cells and of the clear cells lying underneath the zona glomerulosa. They were seen neither in the capsule nor in the inner layers of the adrenal cortex, nor in the medulla. They were spherical, laminated inclusions, sharply defined, surrounded by a clear halo and varying in size from $2 \mu$ to $20 \mu$. They were acidophil by haematoxylin-phloxine-saffron, did not stain with PAS, and exhibited a royal blue colour with luxol fast blue. In accordance with previous investigators (Janigan, 1963; Jenis and Hertzog, 1969; Davis and Medline, 1970), this latter staining technique was found to be especially useful in demonstrating the spironolactone bodies.

By electron microscopy it was possible to follow the evolution of spironolactone bodies from the initial to the final phase. The earliest phase of their development appeared to be the collapse of tubules of the endoplasmic reticulum. The granular and agranular endoplasmic reticulum equally participated in this process (fig 3). The rough-surfaced endoplasmic reticulum membranes, which became incorporated in the laminated formations, shed their ribosomes, retaining them only on the outer- most membrane (figs 4,5 ). The electron opacity of the membranes was increased, mainly due to their collapse and close juxtaposition, at least in the early phases. The arising spherical or ovoid whorls engulfed lipid droplets and other cytoplasmic constituents. The fully developed spironolactone bodies were quite large, varying in size from $10 \mu$ to $20 \mu$. Their central core consisted of an electron-dense amorphous substance which was surrounded by numerous sheets of concentric, tightly packed, smooth-walled membranes (fig 6). At the periphery the membranes were well preserved and showed clearly a trilayered inner structure. The endoplasmic reticulum was the only organelle with which the spironolactone bodies were in continuity (fig 7). Mitochondrial abnormalities never gave rise to such formations. The spironolactone bodies were also easily distinguished from the large osmiophil lipid droplets which were surrounded by several membranes.

The zona glomerulosa cells containing the spironolactone bodies appeared to be viable and even those cells which lodged several cytoplasmic inclusions failed to show ultrastructural features indicating cellular damage (fig 8). The rough-surfaced endoplasmic reticulum was richly developed and the smooth-surfaced endoplasmic reticulum abundant.

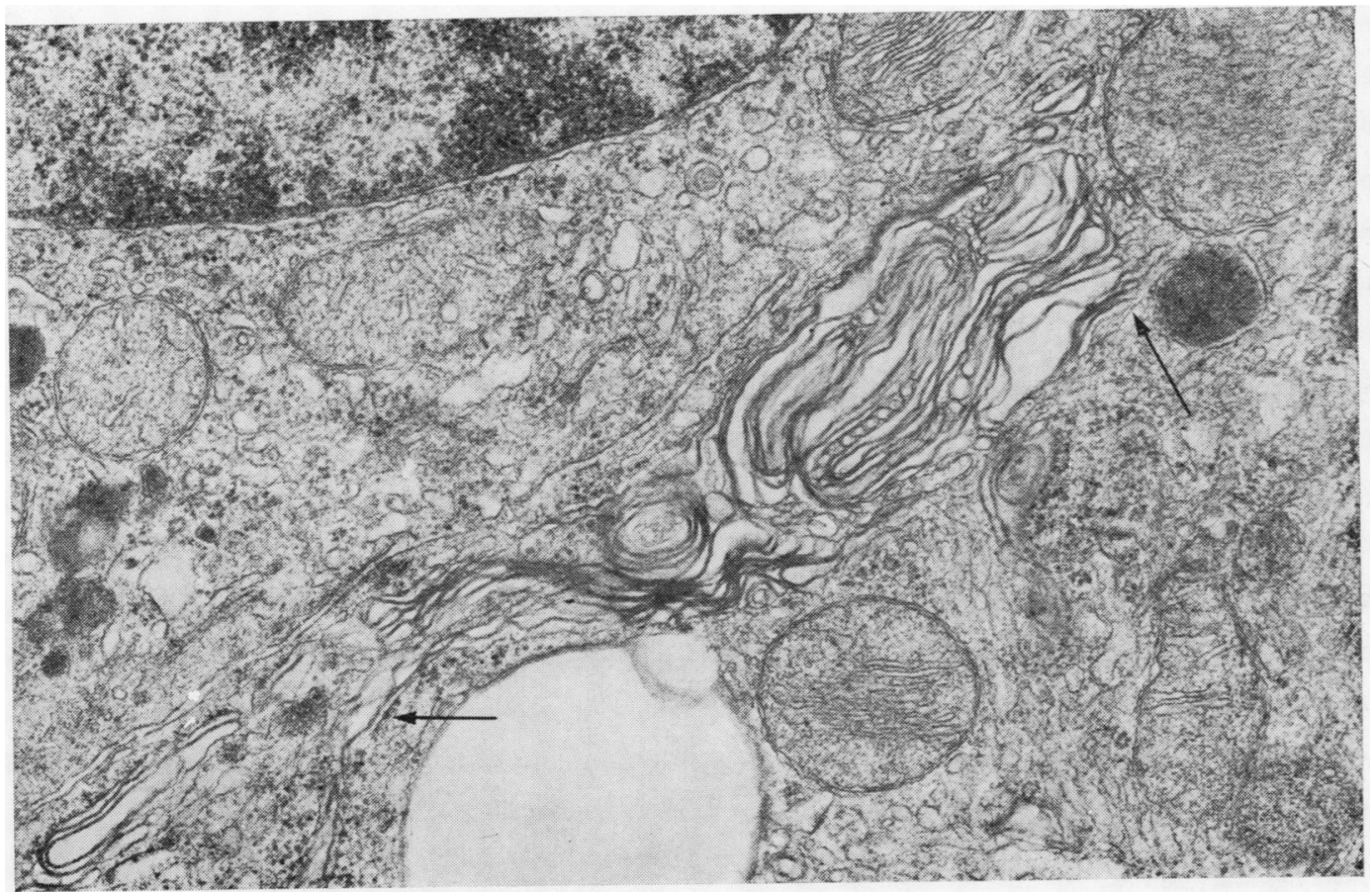

Fig 3 Early developmental phase of a spironolactone body showing collapsed membranes in continuity with smooth and rough surfaced endoplasmic reticulum (arrows). $\times 29000$ 


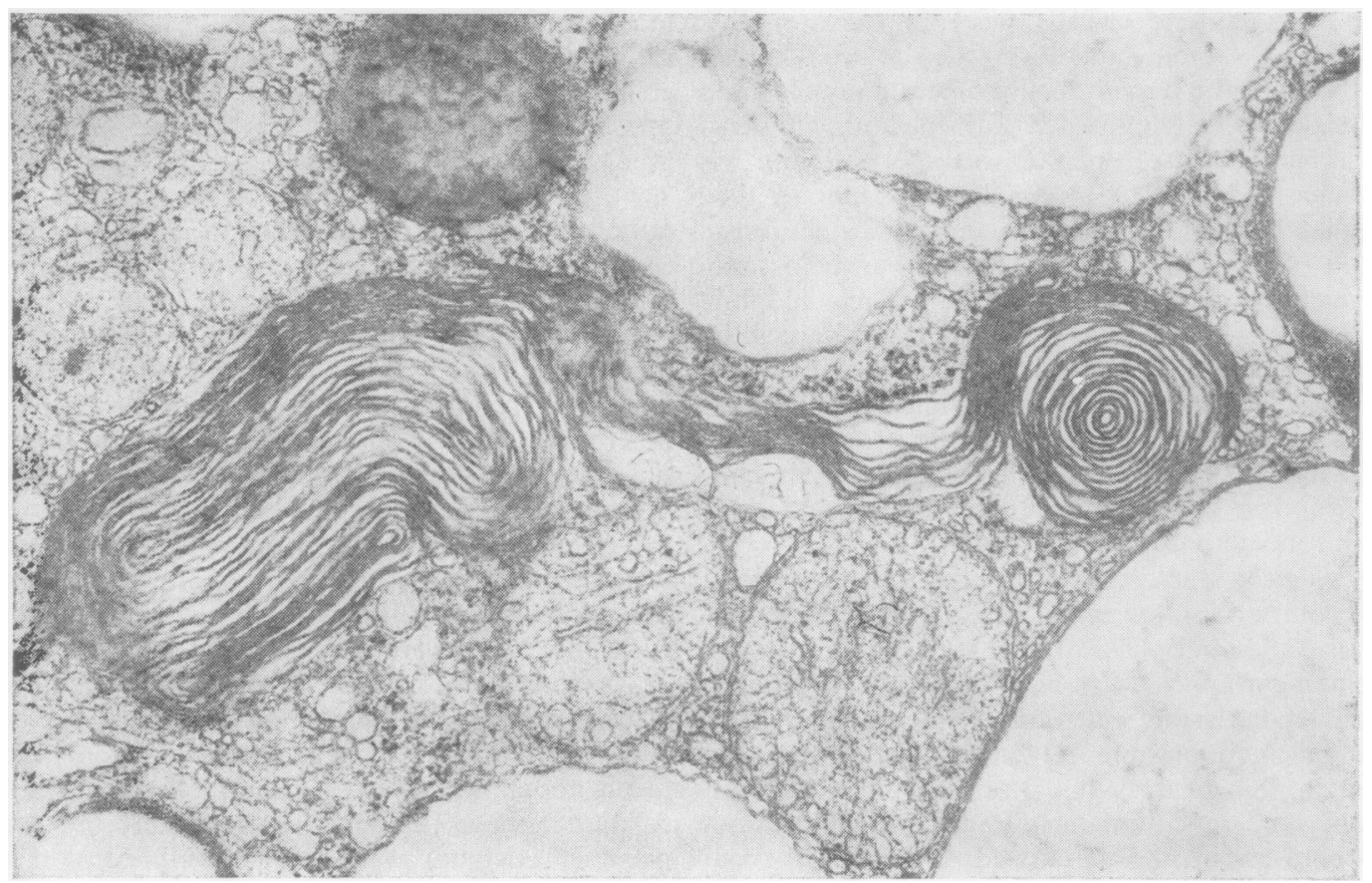

Fig 4 Developing spironolactone body showing contact with smooth walled and ribosome-studded membranes. $\times 35000$

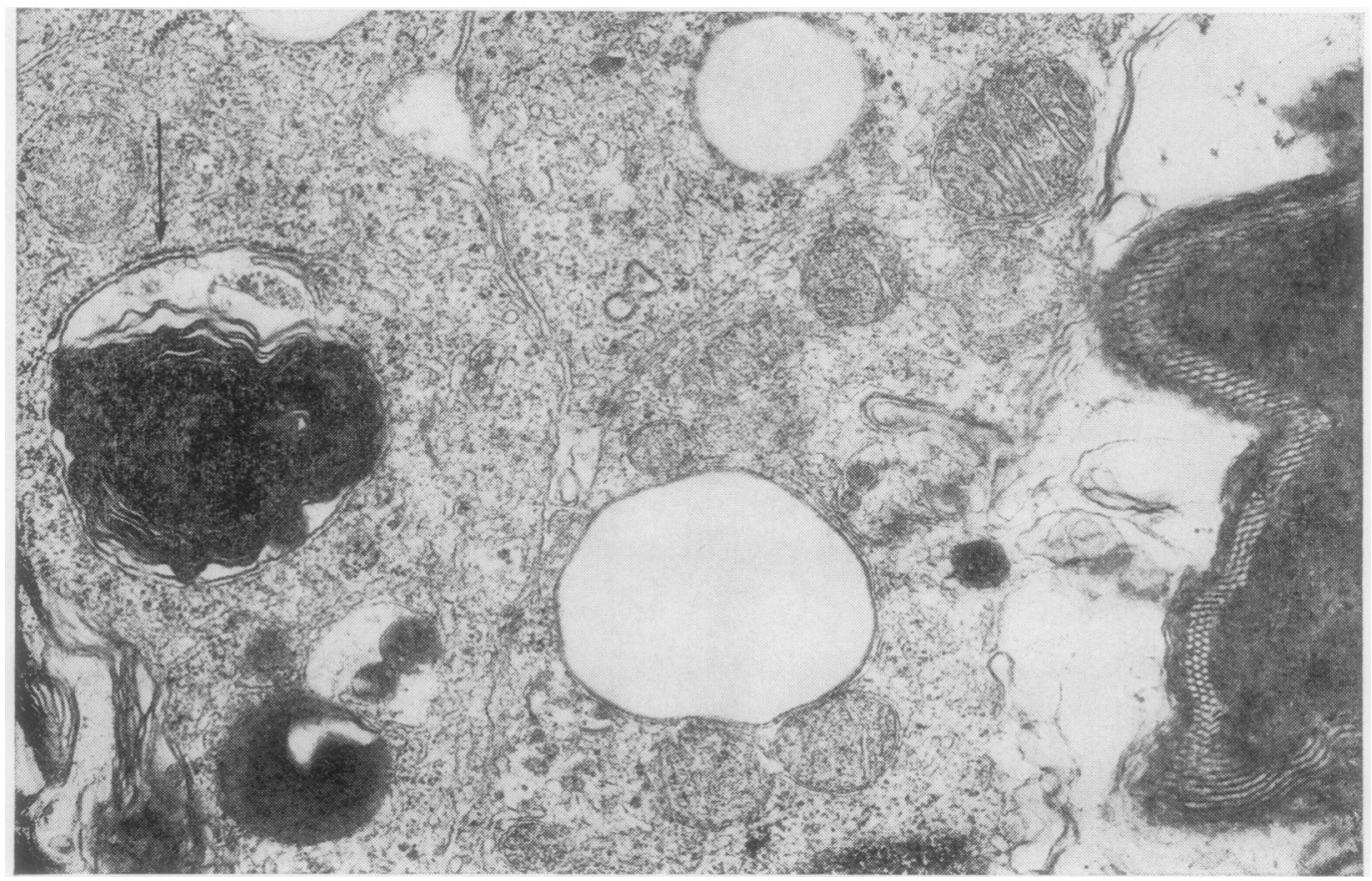

Fig 5 Spironolactone body exhibiting high electron opacity. Its outer membrane is still studded with ribosomes (arrow). $\times 23000$

$8 \overrightarrow{0}$ 을 


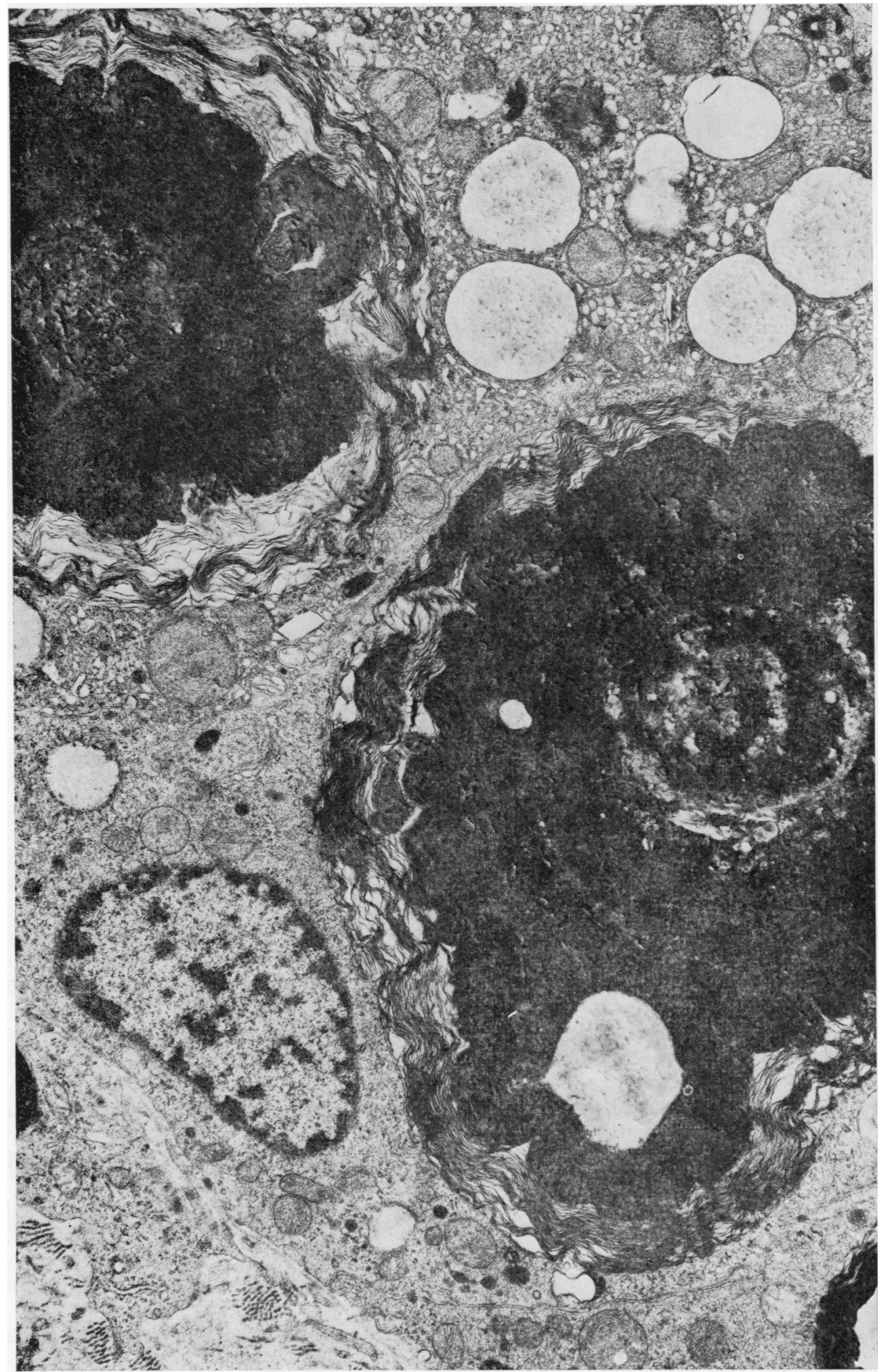

Fig 6 Spironolactone bodies in an advanced phase of development with electron-dense homogeneous substance in their central portions. $\times 10000$ 


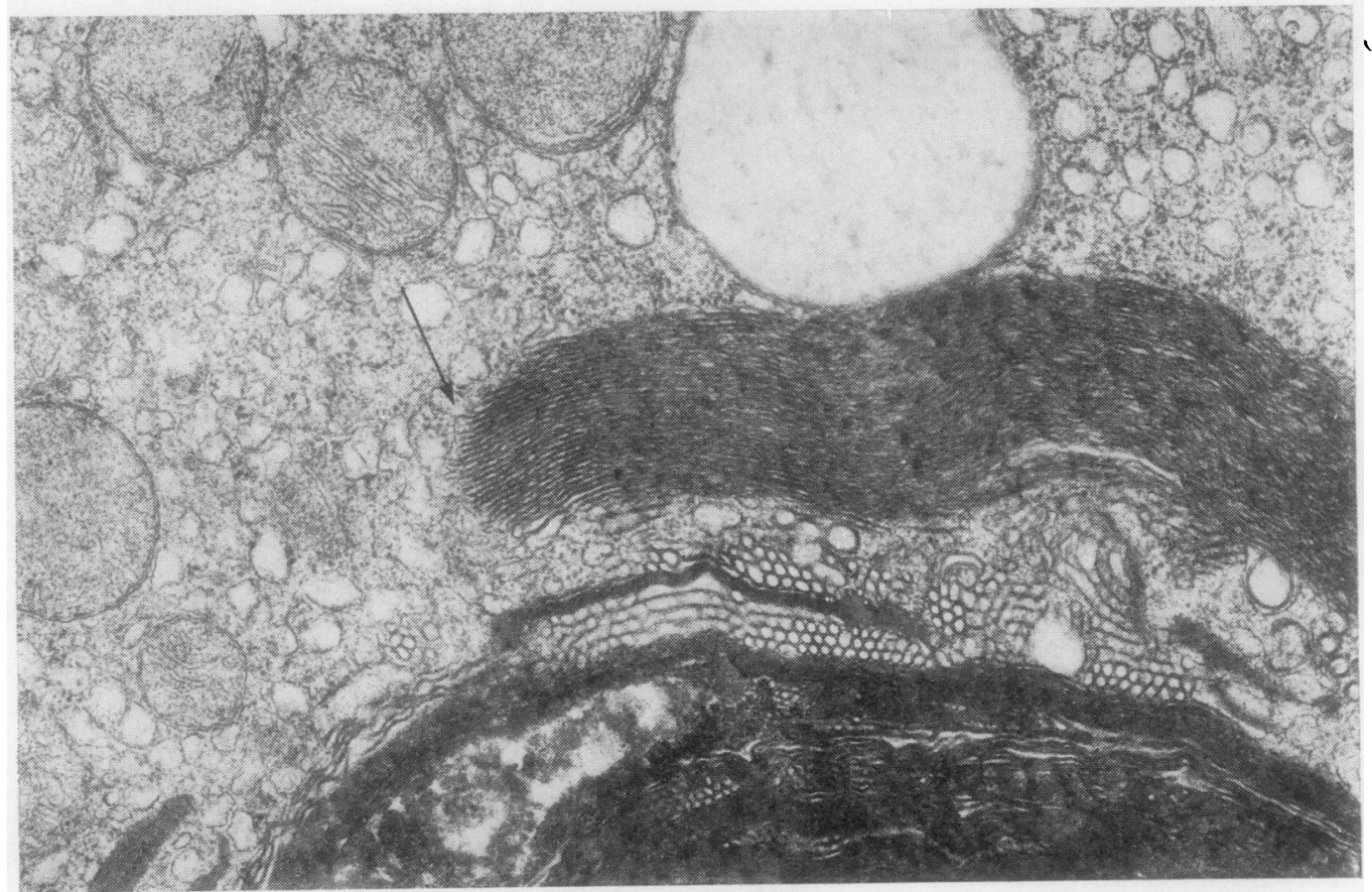

Fig 7 Outer portion of a large spironolactone body. The dense paired membranes show continuity with smooth surfaced endoplasmic reticulum membranes (arrow). $\times 29000$

The mitochondria were rod-shaped or elongated and exhibited lamellar cristae. Several Golgi zones were prominent and the cell membranes were well preserved. The sinusoids did not show any abnormality. In general, the ultrastructure of the zona glomerulosa cells was similar to that described by other authors in the human adrenal gland (Long and Jones, 1967; Luse, 1967).

It should be noted that ultrastructural features suggesting intracellular regression or digestion of spironolactone bodies were not seen. The inclusions were never surrounded by lysosomes. Occasionally, however, distinct spironolactone bodies were detected in the sinusoidal lumina. This finding was interpreted as indicating extrusion of spironolactone bodies from the cells.

\section{Discussion}

The various theories dealing with the morphogenesis of spironolactone bodies are controversial. Jenis and Hertzog (1969) noted that agranular membranous whorls can develop around lipid droplets in the cytoplasm of zona glomerulosa cells of adrenal cortex in man treated over a long period with spironolactone, and suggested that spironolactone bodies originate from the granular endoplasmic reticulum. Davis and Medline (1970) believed that they found connexions between smooth-surfaced endoplasmic reticulum membranes and the lining layers of spironolactone bodies in the cytoplasm of human zona glomerulosa cells, but did not make definite proposals regarding the evolution of these laminated inclusions. Fisher and Horvat (1971)용 claimed to have reproduced spironolactone bodies in the rat adrenal cortex. These authors, offered, however, a different explanation by assuming that spironolactone bodies occur within and arise from mitochondria. They emphasized that Jenis and 0 Hertzog (1969) as well as Davis and Medline (1970) utilized formaldehyde-fixed necropsy material in the course of their electron microscopic studies, thus not permitting interpretations which might be made $\mathcal{N}$ with material more optimally preserved. Rohr- N schneider, Schinko, and Schmiedek (1973) found N cytoplasmic laminated inclusions in the adrenal cortex ${ }_{\sigma}^{\omega}$ of dogs treated with Aldactone. Similar inclusions were, however, detected in the control material, $\frac{C}{\infty}$ hence they were not thought to be identical with spironolactone bodies.

The present study, which was undertaken on a surgically removed, immediately fixed human adrenal 


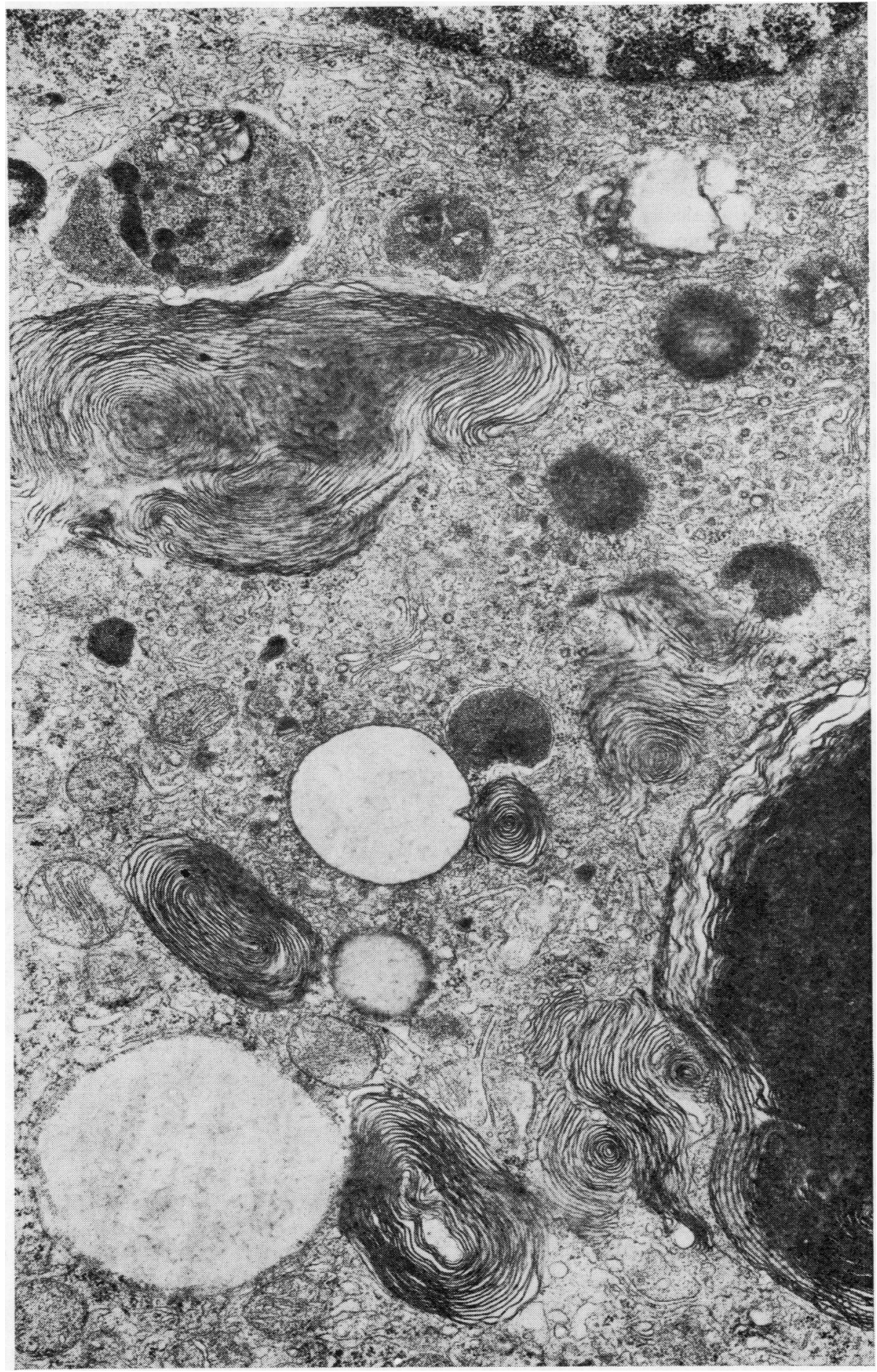


cortex, conclusively proves that spironolactone bodies derive from granular and agranular endoplasmic reticulum membranes. They can be distinguished from myelin figures of mitochondrial origin and from membrane-surrounded lipid bodies. Myelin figures are usually much smaller, they do not have a central amorphous electron-dense core, and are ofter continuous with mitochondrial membranes. The membrane-surrounded lipid bodies will not be described here in detail. Suffice to say that they are of mitochondrial origin. The internal compartments of mitochondria gradually transform into lipid droplets leaving the limiting membranes behind. The various steps of this process were described by Marek, Thoenes, and Motlik (1970) in the rat adrenal cortex following aminoglutethimide treatment and were also seen in the present material. Compared with these two formations spironolactone bodies were usually much larger, most of them possessing a central electron-dense amorphous core, and were composed of more numerous, thicker, and denser agranular membranes.

Previous investigators (Jenis and Hertzog, 1969; Davis and Medline, 1970) emphasized the specificity of spironolactone bodies. They assumed that these bodies are specifically inducible only by spironolactone and occur exclusively in the cytoplasm of the zona glomerulosa cells. Because of pharmacological and anatomical specificity it was thought that spironolactone bodies may provide a morphological marker for the zona glomerulosa and possess incorporated spironolactone in their membranes (Jenis and Hertzog, 1969). However, spironolactone bodies may also very rarely occur in the deeper layers of the adrenal cortex and typical fingerprint configurations, indistinguishable from those seen in the zona glomerulosa after prolonged spironolactone treatment, can be detected in the cytoplasm of adrenocortical (Kovacs, Khandekar, Szabo, Garg, and Tuchweber, 1972) and corpus luteum cells (Kovacs, Horvath, Szabo, Garg, and Tuchweber, 1973) of the rat following administration of cycloheximide, a protein synthesis inhibitor. It is also known that large fingerprint-like bodies can be identified in different organs following treatment with various compounds, such as ethionine, aniline, pregnenolone 16-alpha-carbonitrile, triparanol, chloroquine, etc (Steiner, Miyai, and Phillips, 1964; Kovacs, Blascheck, Yeghiayan, Hatakeyama, and Gardell, 1971a; Garg, Kovacs, and Tuchweber, 1972; Hruban, Slesers, and Hopkins, 1972). Shikata, Kanetaka, Endo, and Nagashima, (1972) found fingerprints in several organs of man and rat following the administration of $4.4^{\prime}$-diethylaminoethoxy hexoestrol, a coronary vasodilatator used to alleviate the pain of angina pectoris. The occurrence of genesis of fingerprints was reviewed recently by Steiner et al (1964), Kovacs, Khandeker, $\stackrel{0}{\frac{0}{5}}$ Szabo, Garg, Gardell, and Tuchweber (1971b) and 으․ by Hruban et al (1972). Based on these data it $\vec{F}$ appears that the pharmacological and anatomical $\stackrel{5}{+}$ specificity of spironolactone bodies cannot be accepted.

The functional significance and fate of spirono- $\frac{}{D}$ lactone bodies remain to be elucidated. It is known $\stackrel{2}{2}$ that spironolactone acts primarily on receptors ${ }^{\circ}$ located in the renal tubules and has no obvious $\overrightarrow{0}$ immediate effect on the rate of aldosterone synthesis and release (Liddle, 1958). Prolonged administration $\vec{\omega}$ of spironolactone, however, leads to sodium? diuresis and by activating the renin-angiotensin? system results in stimulation of aldosterone secretion $N_{\sigma}$ (Spark, Dale, Kahn, and Melby, 1969). Several, $\vec{N}$ authors (Jenis and Hertzog, 1969; Davis and 0 Medline, 1970; Fisher and Horvat, 1971) dealing $\stackrel{\oplus}{0}$ with spironolactone bodies supposed that spirono- 0 lactone may directly affect the zona glomerulosa cell. They suggested that correlation exists between the development of spironolactone bodies $\mathbb{\Phi}_{\mathbb{\infty}}$ and increased synthesis of aldosterone and as- $\frac{\mathbb{}}{3}$ sumed that spironolactone bodies are the morpho-logical expressions of a stimulatory action. It is difficult to prove in human material, however, that $\overrightarrow{0}$ the formation of spironolactone bodies is facilitated $\omega$ by preexisting hyperaldosteronism. According 款Jenis and Hertzog (1969) spironolactone causes progressive accumulation of endoplasmic reticulum; it becomes incorporated in the hypertrophic endoplasmic reticulum membranes and interferes with

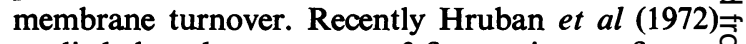
studied the ultrastructure of fingerprint configura- $\frac{3}{3}$ tions occurring in various organs due to the administration of different compounds. They supposed thato these drugs can bind to membranes and can inhibit selectively the activity of lysosomal enzymes con-o cerned with membrane digestion and expressed the view that the fundamental question regarding fingerprint configurations is to understand whyo sequestered membranes resist digestion. It would be interesting to know whether the fingerprint-inducing effect of spironolactone is explicable by this mech- $\rightarrow$ anism.

In the course of the present work several large laminated whorls were detected in the cytoplasm of glomerulosa cells which otherwise did not showo signs indicating cellular damage. Thus, it appearedw that these bodies did not significantly interfere wittp the viability of the cells. Similar conclusions were drawn by Hruban et al (1972) who assumed tha laminated whorls do not represent an irreversible change and they may disappear from the cells. In our studies there was no evidence of regression digestion of spironolactone bodies, accumulation 
of lysosomes, or cellular necrosis. As fingerprints can be recognized occasionally outside the cells, in the sinusoids, it may well be that spironolactone bodies are expelled from the cells.

The authors would like to thank Dr L. Khoo for referring this case, Mr P. Wong, Mr D. Brown, Mrs J. Main, and Miss N. Hui for their technical assistance, and Mrs M. Rowling for invaluable secretarial help.

\section{References}

Davis, D. A., and Medline, N. M. (1970). Spironolactone (Aldactone) bodies: concentric lamellar formations in the adrenal cortices of patients treated with spironolactone. Amer. J. clin. Path., 54, 22-32.

Fisher, E. R., and Horvat, B. (1971). Experimental production of so-called spironolactone bodies. Arch. Path., 91, 471-478.

Garg, B. D., Kovacs, K., and Tuchweber, B. (1972). Ultrastructural changes in the rat liver following protracted treatment with pregnenolone-16 $\alpha$-carbonitrile and digitoxin. Virchows Arch. Abt. B. Zellpath., 12, 61-72.

Hruban, Z., Slesers, A., and Hopkins, E. (1972). Drug-induced and naturally occurring myeloid bodies. Lab. Invest., 27, 62-70.

Janigan, D. T. (1963). Cytoplasmic bodies in the adrenal cortex of patients treated with spirolactone. Lancet, 1, 850-852.

Jenis, E. H., and Hertzog, R. W. (1969). Effect of spironolactone on the zona glomerulosa of the adrenal cortex: light and electron microscopy. Arch. Path., 88, 530-539.

Kovacs, K., Blascheck, J. A., Yeghiayan, E., Hatakeyama, S., and
Gardell, C. (1971a). Adrenocortical lipid hyperplasia induced in rats by aniline: a histologic and electron microscopic study. Amer. J. Path., 62, 17-34.

Kovacs, K., Horvath, E., Szabo, S., Garg, B. D., Tuchweber, B. (1973). Cycloheximide-induced ultrastructural changes in the corpus luteum of rats. Experientia (Basel), 29, 839-840.

Kovacs, K., Khandekar, J. D., Szabó, S., Garg, B. D., Gardell, C., and Tuchweber, B. (1971b). Formations lamellaires dans le cortex surrenalien du rat. Arch. Biol. (Liège), 82, 211-224.

Kovacs, K., Khandekar, J. D., Szabó, S., Garg, B. D., and Tuchweber, B. (1972). Effect of cycloheximide on the rat adrenal cortex. A light and electron microscopic study. Rev. canad. Biol., 31, 105-117.

Liddle, G. W. (1958). Aldosterone antagonists. Arch. intern. Med., 102, 998-1004.

Long, J. A., and Jones, A. L. (1967). Observations on the fine structure of the adrenal cortex of man. Lab. Invest., 17, 355-370.

Luse, S. (1967). Fine structure of adrenal cortex. In The Adrenal Cortex, edited by A. B. Eisenstein, pp. 1-59. Little, Brown, Boston.

Marek, J., Thoenes, W., Motlik, K. (1970). Lipoide Transformation der Mitochondrien in Nebennierenrindezellen nach Aminoglutäthimid (Elipten ${ }^{\circledR}$ Ciba). Virchows. Arch. Abt.B.Zellpath., 6, 116-131.

Rohrschneider, I., Schinko, I., and Schmiedek, P. (1973). Licht-und elektronenmikroskopische Untersuchungen an der Zona glomerulosa des Hundes nach Behandlung mit Spirolacton. Z. ges. exp. Med., 159, 321-332.

Shikata, T., Kanetaka, T., Endo, Y., and Nagashima, K. (1972). Drug-induced generalized phospholipidosis. Acta. path. jap. 22, 517-531.

Spark, R. F., Dale, S. L., Kahn, P. C., and Melby, J. C. (1969). Activation of aldosterone secretion in primary hyperaldosteronism. J. clin. Invest., 48, 96-104.

Steiner, J. W, Miyai, K., and Phillips M. J. (1964). Electron microscopy of membrane-particle arrays in liver cells of ethionine intoxicated rats. Amer. J. Path., 44, 169-190. 